\title{
Results in dissociated vertical deviation after surgery in the Instituto de Oftalmología Fundación de Asistencia Privada Conde de Valenciana IAP
}

\section{Resultados de la desviación vertical disociada posterior a la cirugía en el Instituto de Oftalmología Fundación de Asistencia Privada Conde de Valenciana IAP}

\author{
Diana E. Jiménez-Guerrero ${ }^{*}$, A. Jéssica Vargas-Ortega ${ }^{1}$, Lucrecia Berganza-Canales ${ }^{1}$, \\ Aída Jiménez-Corona ${ }^{2}$ and Claudia E. Murillo-Correa ${ }^{1}$ \\ ${ }^{1}$ Strabismus Department; ${ }^{2}$ Epidemiology and Statistics Department. Instituto de Oftalmología, FAP Hospital Conde de Valenciana, IAP, Mexico City, \\ Mexico
}

\begin{abstract}
Objectives: To determine the results after decompensated DVD surgery at the Instituto de Oftalmología, Fundación de Asistencia Privada "Conde de Valenciana," during the 2004-2014 period. Materials and Methods: Ambispective study, in which the long-term results of DVD-correcting surgery on 40 patients of our Institute were evaluated. Variables of interest: Best-corrected visual acuity, presence of amblyopia, associated strabismus, pre-surgical magnitude of the deviation, type of surgery, surgical result, need for additional surgeries, and follow-up time. Results: Forty patients were studied, of which 28 were female and 12 were male; average age at surgery was 9.6 years, with a mode of 4 years (range 3-35 years). The most frequent associated strabismus was congenital esotropia (60\%), followed by dissociated horizontal deviation in $32.5 \%$. Superior rectus recession was performed in $77.5 \%$ and inferior rectus tucking in $7.5 \%$. Twelve patients had amblyopia (30\%). After surgery, $82 \%$ showed DVD compensation and only 3 patients required additional surgeries. The average follow-up period was 4.8 years (range 1-10). Conclusion: Most patients that underwent surgery for decompensated DVD showed compensation after surgery. Superior rectus recession is the most commonly performed surgery for the treatment of DVD.
\end{abstract}

Key words: Decompensated DVD. Superior rectus recession results. Compensation.

\section{Resumen}

Objetivo: Determinar el resultado posterior a la cirugía de la desviación vertical disociada (DVD) descompensada en el Instituto de Oftalmología Fundación de Asistencia Privada Conde de Valenciana entre los años 2004 y 2014. Materiales y métodos: Estudio ambispectivo en el que se evaluó el resultado a largo plazo de la cirugía para la corrección de la DVD en 40 pacientes de la institución. Variables de interés: Capacidad visual y presencia de ambliopía, patología estrabológica asociada, magnitud preoperatoria de la desviación, cirugía realizada, resultado de la cirugía, requerimiento de más cirugías y tiempo de seguimiento. Resultados: Se estudiaron 40 pacientes, de los cuales 28 eran del sexo femenino y

Correspondence:

*Diana E. Jiménez-Guerrero

La Quemada 45, int 4

Col. Narvarte Oriente, Del. Benito Juárez Date of reception: 31-05-2018

C.P. 03020, Mexico City, Mexico Date of acceptance: 28-11-2018

E-mail: dejg82@yahoo.com

DOI: 10.24875/RMOE.M19000056

Available online: 01-03-2019 Rev Mex Oftalmol (Eng). 2019;93(2):44-49

www.rmo.com.mx 2604-1731/@ 2019 Sociedad Mexicana de Oftalmología. Published by Permanyer México SA de CV. This is an Open Access article under the CC BY-NC-ND license (http://creativecommons.org/licenses/by-nc-nd/4.0/). 
12 eran del sexo masculino; el promedio de edad en el momento de la cirugía fue de 9.6 años, con moda de 4 años (rango 3-35 años). La patología estrabológica asociada más frecuente fue la endotropía no acomodativa (60\%), seguida de la desviación horizontal disociada (32.5\%). Se realizó retroinserción de ambos rectos superiores en el 77.5\%, plegamiento de los rectos inferiores en el 15\%, y transposición anterior de oblicuos inferiores en el 7.5\%. Doce pacientes presentaron ambliopía, correspondiente al 30\%. Posterior a la cirugía, el $82 \%$ presentó compensación de la DVD, solo tres pacientes requirieron cirugías adicionales. El tiempo de seguimiento promedio fue de 4.8 años (rango de 1 a 10 años). Conclusion: La mayoría de los pacientes operados de DVD descompensada en la institución presentan compensación de la misma, posterior a la cirugía. La cirugía más realizada en la institución para tratamiento de la DVD es la retroinserción de rectos superiores.

Palabras clave: DVD descompensada. Resultados retroinserción recto superior. Compensación.

\section{Introduction}

Dissociated vertical deviation (DVD) is a bilateral phenomenon that presents a movement of elevation, abduction and excyclotorsion when the examiner occludes one of the eyes, and then a movement of restitution (incyclotorsion, adduction and depression), when it is de-occluded. It is usually more noticeable in the abducted eye during lateroversion, when this is the most affected eye, since it is asymmetric. In addition, DVD can be classified as "compensated", when it is triggered only by dissociation of the image or inattention, and as "decompensated" when the deviation is constant or intermittent, which occurs in approximately $10 \%{ }^{1}$.

It is associated in almost $70 \%$ of the cases with esotropia, and is usually accompanied by latent nystagmus in 50\%, according to Anderson ${ }^{2}$. It can also be associated with inferior oblique hyperfunction in $27.8 \%$, according to Campomanes, et al. ${ }^{3}$, as well as hyperfunction of superior oblique muscles in 20 to $30 \%$, according to Acosta-Silva ${ }^{4}$, and $18.5 \%$, according to Campomanes, et al. ${ }^{3}$. This is the reason why DVD can originate some $A$ and V syndromes ${ }^{1}$. Something clear about DVD is the high risk of amblyopia in decompensated cases. It is a phenomenon of cortical involvement and its causes have not been fully clarified, although many theories have been postulated like the ones from Scobee (bilateral paresis of the inferior rectus) ${ }^{5}$, Posner (muscle tone anomaly due to pathological ocular dominance) ${ }^{3}$ and Bielschowsky (alteration of vertical vergences) ${ }^{6}$.

Although DVD can be found in patients with normal binocularity ${ }^{7}$, it is often associated with congenital esotropia and, less frequently, accommodative esotropia, exotropia, and sensory heterotropias ${ }^{2}$. It has also been described associated with Duane syndrome ${ }^{8}$ and congenital exotropia, a rare anomaly. ${ }^{9}$ According to Von Noorden, the age at diagnosis of DVD is between 2 and 5 years, which is the age at which most horizontal deviations are surgically corrected ${ }^{10}$.
Surgical treatment of DVD has varied greatly with time. Some methods have been preserved, but other innovative aspects have been introduced for its management. Currently, the management depends largely on the presence or absence of hyperfunction of the oblique muscles, as well as visual acuity and visual capacity, and the presence or absence of amblyopia. Regarding surgical outcomes, Romero-Apis reports a decrease in DVD magnitude (without disappearance) of $60 \%$ in one of his publications, observing a total compensation of the pathology in $27 \%$, and regression to the initial DVD magnitude in $10 \%{ }^{11}$. Regarding superior rectus recession (SRR), one study showed that 23 of the 32 patients selected for this study had significant aesthetic improvement of the deviation after a 3-year follow-up. None of these patients had a diagnosis of superior rectus paresis. The effectiveness of retroinsertion of the superior rectus in other types of vertical strabismus, in terms of correction of the deviation in prismatic diopters (PD) per millimeter of retroinsertion, and the lesser effect of this technique on a DVD of the same magnitude, are some of the details that differentiate this pathology from other types of strabismus ${ }^{12}$.

In a recent article, Pineles, et al. published a study of 14 patients, who underwent an asymmetric and bilateral anterior transposition of the inferior obliques, achieving an important reduction in the magnitude of the DVD, from a preoperative average of $18 \mathrm{PD}$ up to a postoperative average of $1 \mathrm{PD}^{13}$. There is a Mexican study from 2007 by Arroyo-Yllanes, et al., regarding inferior rectus tucking in the eye with poor vision of 19 patients, of which 10 presented improvement up to $1+$, and the other 9 presented a decrease in magnitude up to $2+$ after the surgical procedure, considering that most of them had DVD magnitudes of $4+^{14}$.

\section{Objective}

To determine the postoperative results of decompensated DVD in the Instituto de Oftalmología, Fundación 
de Asistencia Privada Conde de Valenciana between 2004 and 2014.

\section{Materials and methods}

An ambispective study was carried out. We examined the medical records of all the patients who underwent surgery for the correction of DVD between 2004 and 2014 in the Strabismus department of the Instituto de Oftalmología, Fundación de Asistencia Privada Conde de Valenciana in Mexico City, as well as their surgical descriptions. All the selected patients who met the inclusion criteria were reevaluated to determine their current variables, with pictures and video taken as evidence of this evaluation.

Surgical procedures for the correction of DVD made in the aforementioned time period were retroinsertion of the superior rectus (performed in both eyes, in patients with a mean normal or below normal binocular visual acuity, with disinsertion of the muscles above the tendon, and symmetric or asymmetric retroinsertion, depending on the asymmetry of magnitude and if the preoperative DVD is manifest or latent); tucking of the inferior rectus (for patients with spontaneous DVD in a very amblyopic eye; a suture is placed whose mechanical effect is to fold the muscle over itself, entering on one side of the tendon and exiting on the other, passing through the muscular body to level of the mark left by a tucking maneuver performed with the strabismus hooks, called «kiss and hug maneuver», and finally attaching the suture at the tendon level); and anterior transposition of the inferior oblique (for patients with DVD associated with hyperfunction of the inferior oblique; the muscle is disinserted at the level of its tendon and transposed with a suture next to the inferior rectus).

Because most of the superior rectus retroinsertions were symmetrical (23 of 29), we decided to group the symmetrical and asymmetrical retroinsertions of the superior rectus in a single group. In the same way, because the sample for the other two types of surgical interventions was very small, we also decided to group the unilateral and bilateral inferior rectus tuckings in a group and proceeded in the same way with the anterior transpositions of the inferior obliques.

Our variables of interest were: age at the time of surgery, sex, presence of amblyopia, associated strabismus, preoperative magnitude of the deviation, surgery performed, surgical result (compensated if there was no spontaneous manifestation of the DVD with binocular vision or decompensated if the DVD manifested spontaneously with binocular vision), need for more surgeries and follow-up time.

Inclusion criteria were: 1) patients who underwent surgery for DVD correction at our institution between 2004 and 2014, and 2) patients with a second surgery for residual DVD at our institution. Exclusion criteria were: 1) patients who underwent surgery for the surgical management of DVD with contralateral-associated paralytic pathology due to the risk of incurring in a selection bias, for example, paralysis/paresis of the inferior oblique associated with DVD; 2) patients with incomplete medical records; and 3) patients without a follow-up of at least 6 months.

The magnitude of the DVD was measured under cover test for distance and neutralizing any horizontal deviation (if it was present) and scoring with a "cross" system $(+=$ approximately less than $10 \mathrm{PD}$, $++=$ approximately less than $20 \mathrm{PD},+++=$ approxi mately between 20 and $30 \mathrm{PD}$, and $++++=$ approximately greater than $30 \mathrm{PD}$ ). In addition, and very important, we considered if the patient presented spontaneous DVD with binocular vision. If there was no spontaneous DVD at examination of the study patients, we considered a "compensated" surgical result, and if there was spontaneous DVD, the result was considered as "decompensated".

The sample was obtained considering the percentage of recurrences of the surgical technique used. An alpha (error type I) of 0.05 and an error b (error type II) of $10 \%$ (power of $90 \%$ ) were chosen. The sample consisted of 50 patients for the study group.

A descriptive analysis of all the variables of interest (frequencies and percentages) was carried out, as well as the estimation of standard deviations, medians and modes. The SPSSv15 system was used to determine the statistically significant associations, considering a $p<0.05$. This analysis included Fisher's exact test for the comparison of proportions of the categorical variables, and the Kruskal-Wallis test and the Pearson correlation for the continuous variables.

\section{Results}

Forty patients were included. The average age at the time of surgery was 9.625 years, with a standard deviation of plus or minus 7 years. The mode was 4 years. The median was 7.5 years. Most patients in this study were female $(70 \%)$, and only 12 patients were male $(30 \%)$.

Sixty five percent of the patients in this study had associated non-accommodative esotropia, and $32.5 \%$ of the patients showed dissociated horizontal deviation 

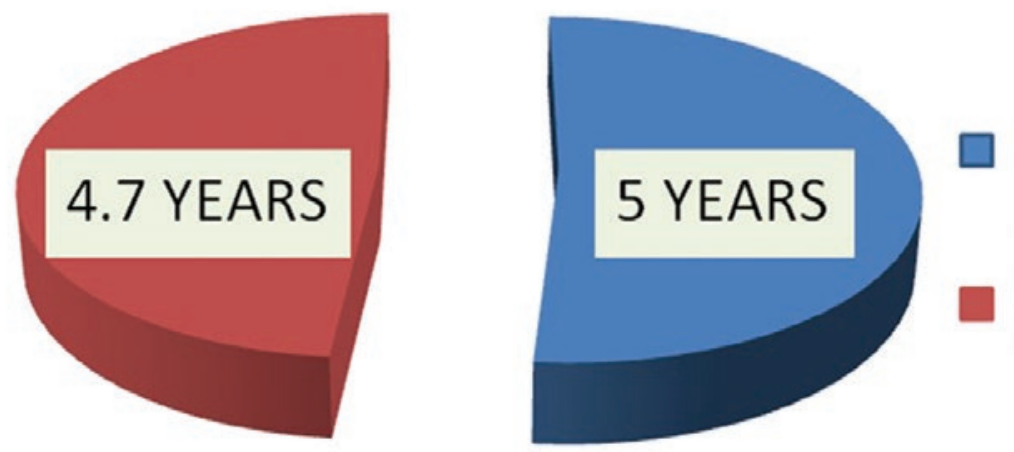

Average follow-up in decompensated patients

Average follow-up in compensated patients

Figure 1. Correlation between follow-up time and surgical results.

as a concurrent pathology. Other types of strabismus barely reach $2.5 \%$, PAE (partially accommodative esotropia).

Retroinsertion of both superior rectus was performed in $77.5 \%(n=31)$ of the patients of this study, compared to anterior transposition of both inferior obliques in 10\% and tucking of one or both inferior rectus in $15 \%$.

The average follow-up time was 4.75 years, with a standard deviation of more or less than 2.244 years, and the median for this variable was 5 years (Fig. 1). Of the total patients in the study, $87.5 \%(n=35)$ had compensated DVD during the postoperative follow-up period. Only 5 patients had decompensated DVD after surgery $(12.5 \%)$.

Overall, 12 patients had amblyopia and 28 did not have amblyopia (70\% non-amblyopic). Of the amblyopic patients, 9 had compensated deviations at the end of the study, and 3, decompensated; of the amblyopic patients, 10 had unilateral amblyopia (2 in the right eye and the others in the left) and 2 had bilateral amblyopia. Of the non-amblyopic patients, 26 were compensated and 2 were decompensated. This correlation was not statistically significant $(p=0.118)$ (Fig. 2).

The average age of patients who did not improve the magnitude of the DVD and remained decompensated was 5.4 years, with a standard deviation of plus or minus 1.02 years and a median of 5 years. The average age of patients who improved was 10.22 years, with a standard deviation of plus or minus 7.27 years and a median of 8 years. This correlation was not statistically significant $(p=0.1568)$.

The most frequent procedure for DVD treatment between 2004 and 2014 was retroinsertion of the superior rectus, with a percentage of decompensation of $13 \%$ for all the patients who underwent this procedure. An inferior rectus tucking was performed in 6 patients, with a decompensation percentage of $15 \%$. Those who

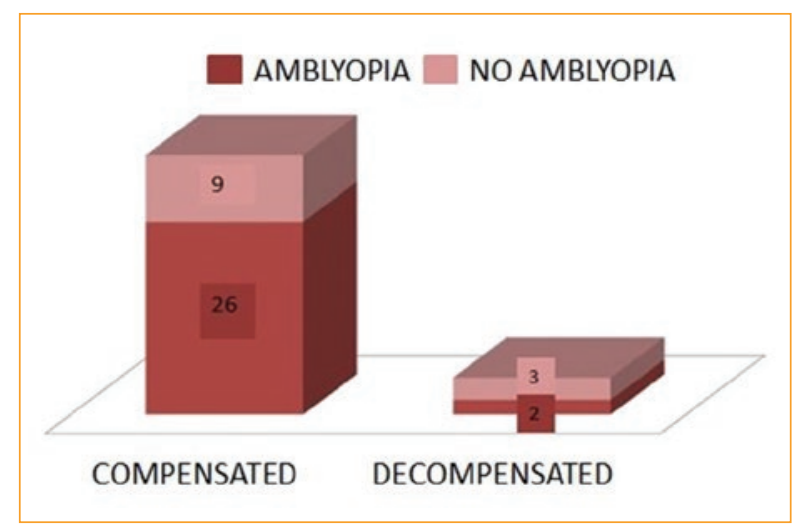

Figure 2. Correlation between surgical results and postoperative best-corrected visual acuity (in terms of absence/presence of amblyopia).

underwent anterior transposition of the inferior obliques did not show decompensation (Fig. 3). In addition, we observed that those who underwent retroinsertion of the superior rectus and remained descompensated, required an average of 1.5 additional surgeries, that ultimately did not help to achieve compensation. There was a case of hypercorrection after inferior rectus tucking. This was not statistically significant $(p=0.768)$.

Of the patients without amblyopia, 19 were female and 8 male. Of the amblyopic patients, 8 were female and 4 male. Regarding the postoperative results, of the 34 compensated patients, 11 were male, and 23 were female. This correlation was not statistically significant ( $p=0.602$ ). Of the decompensated patients, 1 was male, and 4 were female (Fig. 4).

\section{Discussion}

According to the literature consulted for this work, such as the work of Romero-Apis from 1971, DVD 


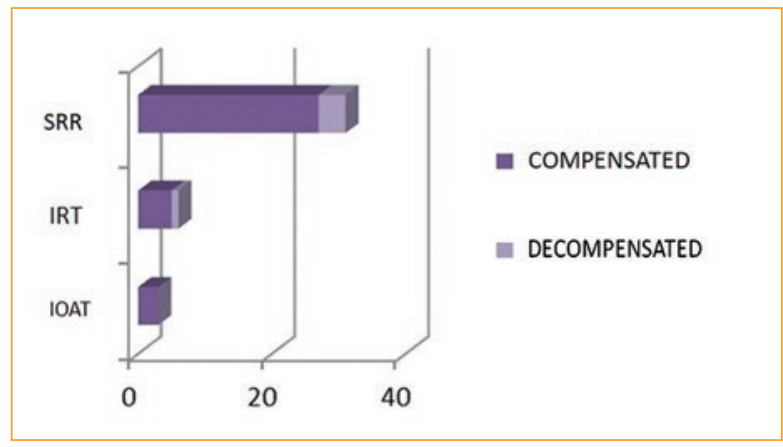

Figure 3. Correlation between the type of surgery and surgical results. IRT inferior rectus tucking;

SRR: superior rectus recession

IOAT: bilateral inferior oblique anterior transposition.

compensation after surgery is achieved in approximately $60 \%{ }^{11}$. In this work, we obtained a compensation of $80 \%$. It is likely that this is due, perhaps, to the refinement of surgical techniques over time and to the sample size. Our result was also very consistent with that found by Esswein, et al. ${ }^{12}$. We did not obtain statistically significant differences regarding the result and type of surgery.

Most patients underwent symmetrical retroequatorial retroinsertion of both superior rectus, because they met the criteria for this surgery, that is, they did not have deep amblyopia in one of the eyes, or they had symmetric amblyopia in the few cases treated in this work. The patients in this study were well selected for the type of surgery performed. There were 2 patients with unilateral amblyopia who underwent unilateral retroinsertion of the superior rectus, one of them with moderate amblyopia. According to Arroyo-Yllanes, et al., in cases with a very deep unilateral amblyopia, the best treatment (and in turn, the least invasive) is tucking of the inferior rectus of the amblyopic eye with decompensated DVD ${ }^{14}$.

In this study, we had 4 patients who required a second surgery due to the persistence of decompensated DVD after the retroinsertion of the superior rectus. This is very similar to the results reported by Magoon, et al., although in this study they only evaluated the results of the correction of decompensated DVD by asymmetric surgery in the superior rectus (based, according to these authors, on the fact that DVD manifests asymmetrically, and without considering the visual acuity of the patients for decision-making) ${ }^{15}$.

We had a low hypercorrection rate, compared to the one reported by Braverman, et al. They had 4 cases of hypercorrection associated with superior rectus surgery,

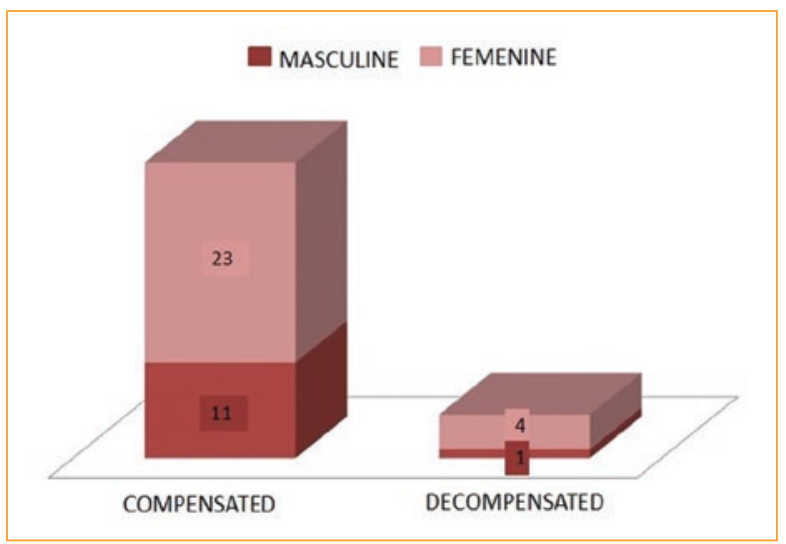

Figure 4. Correlation between sex and surgical results.

while our hypercorrection cases were subsequent to inferior rectus surgery ${ }^{16}$.

Something to consider is that, in this work, there was no risk of selection bias for the follow-up variable, since the patients from different years of follow-up were evenly distributed among the compensated and decompensated groups, and we did not find publications that considered this difference.

This study could have been a simple retrospective study, but we decided to do it as up-to-date as possible, reevaluating patients who in most cases had been lost in follow-up for more than 2 years, to reassess their current status and registering it with pictures and videos, which makes it a study with retrospective roots, but with a descriptive and up-to-date analysis. One of the limitations of this study is the somewhat small sample, especially for patients managed with tucking of the inferior rectus and anterior transposition of the inferior obliques, although we consider that this would not have changed our results.

\section{Conclusions}

The success of the surgery for DVD correction is good in our institution, with higher success rates than in previous published studies. The most frequent performed surgery in our institution is the retroinsertion of the superior rectus. The tucking of the inferior rectus is done less frequently, according to the size of our sample. The presence of amblyopia did not determine the success or failure of the surgeries in this study, as this correlation was not statistically significant. The age at surgical correction was not associated with statistically significant results either. If the sample was larger, we would probably see changes regarding frequency, but our surgical 
success would probably be the same. There was no correlation between the pathologies associated with DVD and surgical success in the medium and long term. To our knowledge, this is the first study in our country that compares surgical techniques, postoperative best-corrected visual acuity, associated diagnoses, results and postoperative follow-up to determine the success rates of surgical correction for DVD. It is necessary to carry out more studies of this nature in other institutions, to determine population trends in terms of results after DVD surgery.

\section{Conflicts of interest}

The authors declare no conflicts of interest.

\section{Ethical disclosures}

Protection of human and animal subjects. The authors declare that no experiments were performed on humans or animals for this study.

Confidentiality of data. The authors declare that no patient data appear in this article.

Right to privacy and informed consent. The authors declare that no patient data appear in this article.

\section{References}

1. Romero-Apis D, Castellanos-Bracamontes A, Acosta-Silva M. Estrabismos disociados. En: Temas Selectos de Estrabismo. p. 49-60.

2. Kutluk S, Avilla CW, von Noorden GK. The prevalence of dissociated vertical deviation in patients with sensory heterotropia. Am J Ophthalmol. 1995;119:744.

3. Campomanes-Eguiarte G, Castellanos-Bracamontes A, González y Gutiérrez L. Desviación vertical disociada. En: Actualidades del Estrabismo Latinoamericano. Congreso Latinoamericano de Estrabismo, CIBA Vision. 1998;241-52

4. Acosta-Silva M. Cirugía de cuatro oblicuos para DVD y síndrome en "A". En: Temas Selectos de Estrabismo. 2. ${ }^{\text {aed }}$. 2005; p. 125.

5. Scobee RG. The oculorotary muscles. St. Louis: The CV. Mosby and Co., 1947; p. 145.

6. Bielschowsky A. Disturbances of the vertical motor muscles of the eye. Arch Ophthalmol. 1938;20:175-200.

7. Van Rijn LJ, ten Tusscher MP, de Jong I, Hendrikse F. Assymetrical vertical phorias indicating dissociated vertical deviation in subjects with normal binocular vision. Vision Res. 1998;38(19):2973-8.

8. Rimmer S, Katz B. Dissociated vertical deviation in a patient with Duane's retraction syndrome. J Clin Neuro Ophthalmol. 1990;10:38.

9. Metz HS, Norris H. Cyclotorsional diplopia following retinal detachment surgery. J Pediatr Ophthalmol Strabismus. 1987;24:287.

10. Von Noorden GK, Campos EC. Cyclovertical Deviations. En: Binocular vision and ocular motility. Theory and management of strabismus. $6^{\text {th }}$ ed. Mosby, 2002; p. 378-85.

11. Romero-Apis D. Early surgery results in strabismus. J Pediatr Ophthalmol. 1971;8:93.

12. Esswein MB, von Noorden GK, Coburn A. Comparison of surgical methods in the treatment of dissociated vertical deviation. Am J Ophthalmol. 1992;113:287

13. Pineles SL, Vélez G, Vélez FG. Asymmetric inferior oblique anterior transposition for incommitant asymmetric dissociated vertical deviation. Graefes' Arch Ophthalmol. 2013;251(11):2639-42.

14. Arroyo-Yllanes ME, Escanio-Cortés ME, Pérez-Pérez JE, Murillo-MuriIlo L. Plegamiento del recto inferior unilateral para el tratamiento de la desviación vertical disociada. Cirugía y cirujanos. 2007;75(1):7-12.

15. Magoon E, Cruciger M, Jampolsky A. Dissociated vertical deviation: an asymmetric condition treated with large bilateral superior rectus recession. J Pediatr Ophthalmol Strabismus. 1982;19(3):152-6.

16. Braverman DE, Scott WE. Surgical correction of dissociated vertical deviations. J Pediatr Ophthalmol. 1977;14(6):337-42. 